I. Weets $\cdot$ I. Truyen $\cdot$ I. Verschraegen •

B. Van der Auwera - J. De Schepper · H. Dorchy •

M.-C. Lebrethon - L. Van Gaal • P. Van Rooy •

D. G. Pipeleers · F. K. Gorus •

Belgian Diabetes Registry

\title{
Sex- and season-dependent differences in C-peptide levels at diagnosis of immune-mediated type 1 diabetes
}

Received: 20 September 2005 / Accepted: 14 December 2005 / Published online: 29 March 2006

(C) Springer-Verlag 2006

\begin{abstract}
Aims/hypothesis: The incidence of type 1 diabetes varies according to age, sex and season of diagnosis. We investigated whether these and other clinical, biological and anthropometric parameters were correlated with residual beta cell function in newly diagnosed patients, since it is possible that the nature of external and/or genetic disease accelerators may be (partly) reflected in the inaugural disease presentation. Materials and methods: The correlates of random Cpeptide levels sampled shortly after diagnosis (median
\end{abstract}

I. Weets $(\bowtie) \cdot$ I. Truyen $\cdot$ B. Van der Auwera

D. G. Pipeleers · F. K. Gorus

Diabetes Research Centre, Brussels Free University,

Laarbeeklaan 103,

1090 Brussels, Belgium

e-mail: ilse.weets@az.vub.ac.be

Tel.: +32-2-4775030

Fax: +32-2-4775047

I. Verschraegen

Department of Clinical Chemistry,

Academic Hospital of the Brussels Free University,

Brussels, Belgium

\section{J. De Schepper}

Department of Paediatrics,

Academic Hospital of the Brussels Free University,

Brussels, Belgium

H. Dorchy

Department of Diabetology,

Children's University Hospital Queen Fabiola,

Brussels, Belgium

M.-C. Lebrethon

Department of Paediatrics,

University Hospital and La Citadelle Hospital,

Liège, Belgium

L. Van Gaal

Department of Endocrinology, University Hospital Antwerp,

Edegem, Belgium

P. Van Rooy

Department of Diabetology, Middelheim Hospital,

Antwerp, Belgium [interquartile range]: 3 [0-14] days) were studied by multivariate analysis in 1,883 islet-antibody-positive diabetic patients aged $<40$ years who were diagnosed between 1989 and 2000. Results: Higher C-peptide levels (above percentile 50 of patients) were associated with older age at diagnosis, female sex, diagnosis in the high-incidence season (October to March), less-decreased BMI (expressed as a standard deviation score), lower insulin requirements after stabilisation, lower prevalence of ketonuria and a less-increased glycaemia at diagnosis (all $p<0.001$ ). C-peptide levels were not correlated with calendar year at diagnosis, duration of symptoms prior to diagnosis, $H L A-D Q 2 / D Q 8$ genotype or islet antibody status. Conclusions/interpretation: Sex- and seasondependent differences in residual functional beta cell mass and/or insulin resistance have been identified at diagnosis of type 1 diabetes. They may reflect differences in disease-precipitating external or lifestyle factors and should be further investigated longitudinally in prediabetes to further identify putative aetiological factors, which may provide targets for prevention.

Keywords Age - Autoantibodies - Clinical presentation . C-peptide $\cdot H L A-D Q$ genotype $\cdot$ Phenotype $\cdot$ Season $\cdot$ Sex . Type 1 diabetes

Abbreviations BDR: Belgian Diabetes Registry . GADA: glutamate decarboxylase antibodies - IA2A: isulinoma-associated protein-2 - IAA: insulin autoantibodies - ICA: islet cell cytoplasmic antibodies . $\mathrm{P}_{50}$ : percentile $50 \cdot \mathrm{SDS}$ : standard deviation score

\section{Introduction}

Type 1 diabetes is a multifactorial disease caused by a near complete destruction of beta cells and triggered or promoted by largely unknown external factors in genetically susceptible individuals $[1,2]$. The disease presents along a clinical spectrum ranging from acute life-threatening diabetes to slowly progressing forms [3]. Compared 
with childhood-onset diabetes, adult-onset disease displays less-prominent insulitis and better-preserved beta cell mass, less-severe clinical presentation with a striking male-to-female excess, a lower frequency of the $H L A$ $D Q 2 / D Q 8$ genotype and of autoantibodies against insulin (IAA), islet cell cytoplasm (ICA) and/or insulinomaassociated protein 2 (IA2A) but a higher frequency of autoantibodies against glutamate decarboxylase (GADA) [3-6].

The question arises whether differences in inaugural phenotype merely reflect less acute and less severe immune aggression of beta cells with increasing age at diagnosis (possibly a surrogate for a longer preclinical phase) or, alternatively, phenotypic variation according to covariates of age at clinical onset such as $H L A-D Q$ susceptibility or sex, which may be implicated in distinct pathogenic mechanisms [3-6].

The male-to-female excess in diabetes is mainly confined to the winter season, since the incidence peak of type 1 diabetes during that period is largely restricted to male patients diagnosed after age 10 and without the HLA$D Q 2 / D Q 8$ genotype [7]. This suggests a larger contribution of season-dependent aetiological factors in precipitating the disease process in male patients. If so, this aetiological diversity according to sex may lead to sex-dependent differences in clinical presentation. We have therefore investigated the possible correlates of random C-peptide at diagnosis, considering also possible confounders such as age and $H L A-D Q$ genotype.

\section{Materials and methods}

Subjects

Between 1 January 1989 and 31 December 2000, a total of 3,271 diabetic patients aged $0-39$ years were prospectively registered by the Belgian Diabetes Registry (BDR). Of the 3,271 patients, 1,883 subjects (Fig. 1) fulfilling the following criteria were included: (1) Belgian residency for at least 6 months prior to diagnosis (excluded: $n=0) ;(2)$ primary diabetes (no gestational, secondary or unknown type of diabetes: $n=102$ ); (3) of European extraction (excluded: $n=132$ ); (4) demographic data and blood samples within 18 months after diagnosis (excluded: $n=447$ ); (5) positivity for $\geq 1$ type of autoantibody (IAA, ICA, GADA, IA2A) (excluded: $n=414$ ); and (6) serum for central C-peptide measurement (excluded: $n=293$ ). BMI was expressed as a standard deviation score (SDS) [5, 8]. Comparison with a subregion (Antwerp district) with nearcomplete case ascertainment (94\%) has demonstrated that the Belgian group, with incomplete ascertainment (52\% over the entire study period), is representative of the Belgian diabetic patients with diagnosis before age 40 years in terms of demographic, clinical and biological criteria [4]. Median (interquartile range) sampling time after diagnosis was $3(0-14)$ days.

Ethics committees of the BDR and participating universities approved the study. Informed consent was

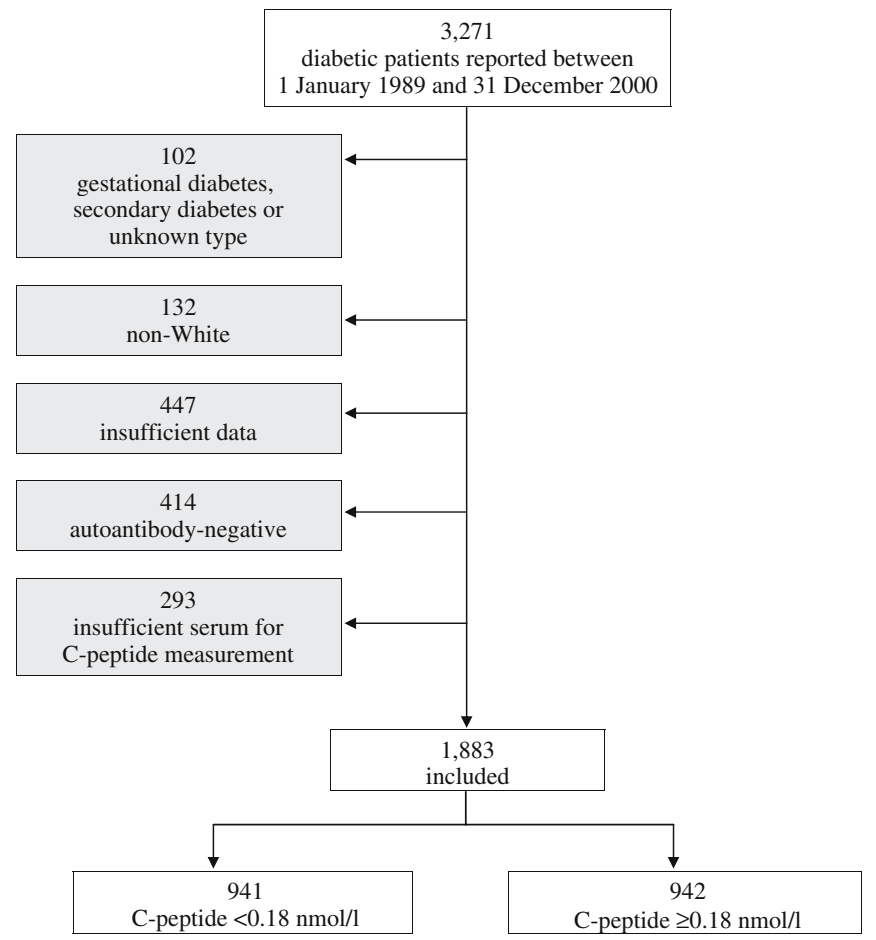

Fig. 1 Number of included diabetic patients aged 0-39 years according to random C-peptide levels at diagnosis of immune-mediated diabetes

obtained from each subject and/or its parents in accordance with the Helsinki Declaration.

\section{Biological markers}

ICA were determined by indirect immunofluorescence, IAA, GADA, IA2A by liquid phase radiobinding assay and $H L A-D Q$ polymorphisms by allele-specific oligonucleotide genotyping [9]. Random C-peptide levels were determined on serum samples collected for analysis of diabetesassociated autoantibodies. The C-peptide assay was performed with a commercial kit $\left({ }^{125} \mathrm{I}\right.$-human C-peptide and guinea-pig anti-human C-peptide serum; Linco, MO, USA; lower detection limit $20 \mathrm{pmol} / \mathrm{l}$ ) [10]. Glycaemia at diagnosis was determined with hexokinase $(70 \%$ of laboratories), glucose oxidase (29\%) or glucose dehydrogenase $(1 \%)$ methods. In the obligatory Belgian national quality assurance programme for clinical laboratories, the $\mathrm{CV}$ for all participants together was $2.7 \%$ at the level of $15.0 \mathrm{mmol} / \mathrm{l}$ glucose.

\section{Statistical analysis}

Clinical and biological characteristics of antibody-positive patients were studied after stratification for $\mathrm{C}$-peptide level (patients with C-peptide levels below percentile $50\left[\mathrm{P}_{50}\right]$ $[<0.18 \mathrm{nmol} / \mathrm{l}]$ vs patients with $\mathrm{C}$-peptide levels above $\mathrm{P}_{50}$ $[\geq 0.18 \mathrm{nmol} / 1]$ ) (Fig. 1). Differences between groups were assessed by a Mann-Whitney $U$ test for continuous 
variables and by a $\chi^{2}$-test with Yates' correction, or Fisher's exact test, whenever appropriate, for categorical variables. Forward stepwise logistic regression analysis was performed with C-peptide as dependent categorical variable, firstly with inclusion of all variables with $p \leq 0.10$ in the age-adjusted univariate analysis (Table 1) and secondly with inclusion of interactions for significant parameters in the multivariate model. Forward stepwise multiple linear regression analysis was performed with logtransformed C-peptide levels as dependent continuous variable with the same independent variables as in the logistic regression analysis. Statistical tests were performed two-tailed using SPSS for Windows 11.5 (SPSS Inc., Chicago, IL, USA) for personal computers and considered significant at $p<0.05$ (multivariate analysis) or, in the case of $k$-independent univariate comparisons, at $p<0.05 / k$ (Bonferroni correction).

\section{Results}

Compared with patients with C-peptide levels below $\mathrm{P}_{50}$, patients with higher C-peptide levels were older at diagnosis, had a less-decreased BMI-SDS, needed less insulin after stabilisation, had a lower prevalence of ketonuria and less-increased glycaemia at diagnosis (all $p<0.001$ ) (Table 1). Furthermore, women were significantly overrepresented $(p<0.001)$ in the group with $\mathrm{C}$ peptide levels above or equal to $\mathrm{P}_{50}$ (48 vs $38 \%$ in the group with $\mathrm{C}$-peptide $<\mathrm{P}_{50}$ ). Despite the overall older age of male patients [5] their random C-peptide levels were significantly lower than those of female patients (median [interquartile range]: $0.16[0.09-0.28] \mathrm{nmol} / 1$ vs 0.19 $[0.11-0.31] \mathrm{nmol} / \mathrm{l}$ in females; $p<0.001)$.

Patients with $\mathrm{C}$-peptide levels above $\mathrm{P}_{50}$ were more often diagnosed in the high-incidence season between October and March $(p<0.001)$ (Table 1). There were no differences in the prevalence of the HLA-DQ2/DQ8 genotype and diabetes-associated autoantibodies except for a lower frequency of IAA-positivity $(p<0.001)$ and a lower frequency of multiple antibody-positivity in patients with a random C-peptide above $\mathrm{P}_{50}$ (Table 1). Antibody levels of ICA and IAA (but not GADA and IA2A) were significantly lower in patients with a random C-peptide above $\mathrm{P}_{50}$ (not shown). The year of diagnosis did not influence C-peptide levels (Table 1). After adjustment for the age difference between both C-peptide groups, similar results were found using univariate logistic regression analysis, except that the difference in antibody levels (not shown), IAA-prevalence and multiple antibody-positivity disappeared (Table 1). In patients with better-preserved Cpeptide levels, who are overall older at diagnosis and more often diagnosed in the high-incidence period ( $p<0.001$ vs those with $\mathrm{C}$-peptide $<\mathrm{P}_{50}$ ) - but not in those with lesspreserved C-peptide (not shown) - male subjects had lessdecreased BMI-SDS and lower insulin needs than female patients (median [interquartile range] BMI-SDS: -0.21 $[-1.03$ to 0.65$]$ vs $-0.39[-1.17$ to 0.31$]$ in females; $p=0.001$;

Table 1 Demographic, clinical and biological characteristics of 1,883 patients according to random C-peptide level at diagnosis

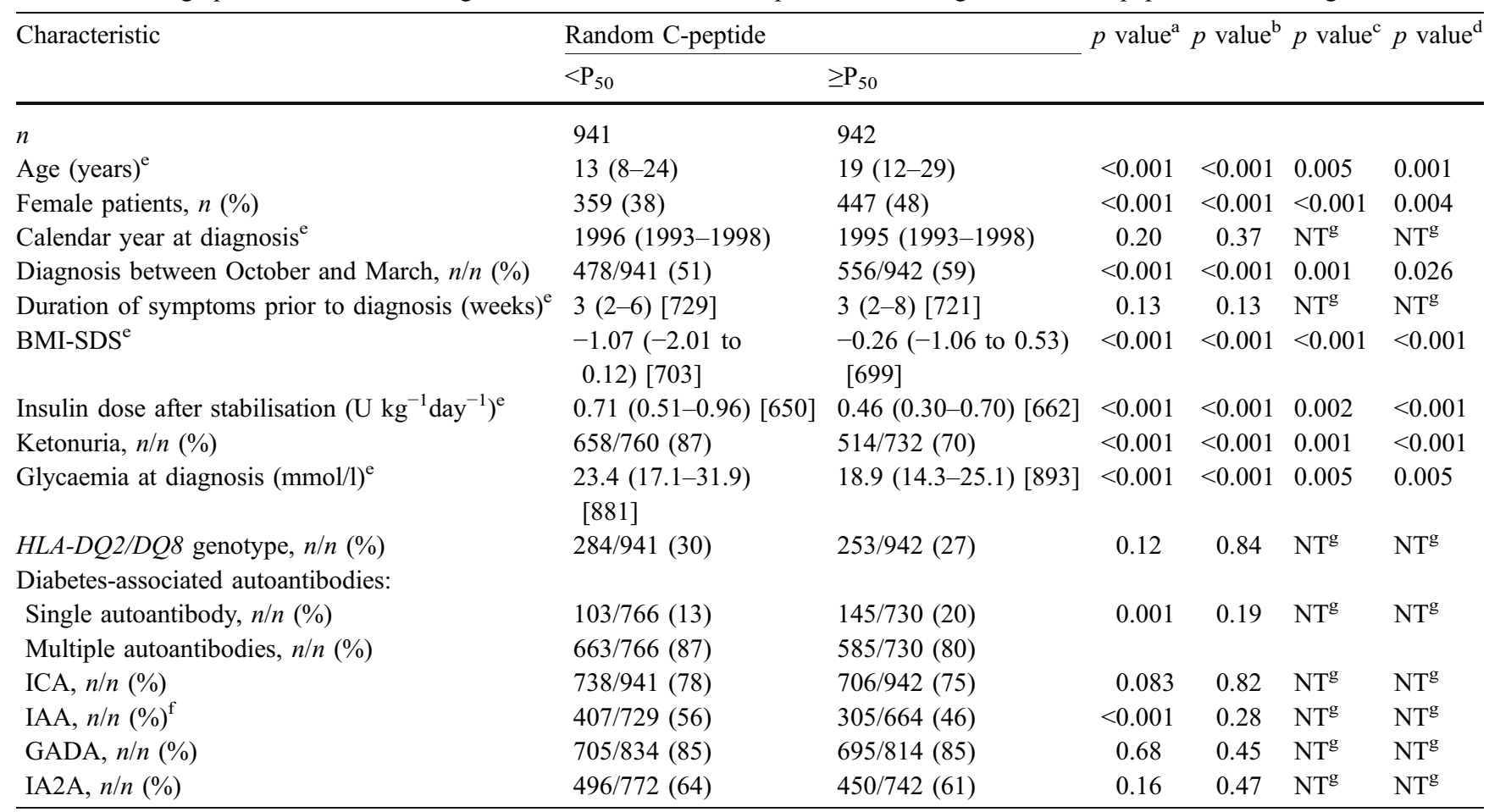

\footnotetext{
${ }^{\mathrm{a}, \mathrm{b}}$ The threshold for statistical significance is $p<0.05 / 15$ or $p<0.0033$ (Bonferroni adjustment); ${ }^{\text {a }}$ unadjusted univariate analysis; ${ }^{\mathrm{b}}$ age-adjusted univariate logistic regression analysis; ${ }^{\mathrm{c}}$ multivariate stepwise logistic regression analysis; ${ }^{\mathrm{d}}$ stepwise multiple linear regression analysis using log-transformed C-peptide levels as dependent continuous variable; ${ }^{\mathrm{e}}$ median (interquartile range) $[n]$; ${ }^{\mathrm{f}}$ determined only in blood samples taken within 7 days after start of the insulin treatment; ${ }^{g} N T$ Not tested because $p>0.10$ in $^{\mathrm{b}}$
} 
median [interquartile range] insulin dose: 0.43 [0.28$0.63] \mathrm{U} \cdot \mathrm{kg}^{-1} \cdot \mathrm{day}^{-1}$ vs $0.51[0.32-0.75] \mathrm{U} \cdot \mathrm{kg}^{-1} \cdot \mathrm{day}^{-1}$ in females; $p<0.001$ ).

Both types of multivariate analysis indicated that higher C-peptide levels were associated with older age at diagnosis, female sex, diagnosis between October and March, less-decreased BMI-SDS, lower insulin doses, less-frequent ketonuria and less-increased glucose levels (Table 1). Logistic regression analysis also confirmed or disclosed several interactions: (1) the relationship of C-peptide levels with insulin dose was also dependent on sex (lower doses in males) and presence/absence of ketonuria (lower doses in the absence of ketonuria); (2) season was also determined by age and glycaemia at diagnosis (lower in winter in $<\mathrm{P}_{50}$ group but not in $\geq \mathrm{P}_{50}$ group); and (3) BMI-SDS was additionally influenced by sex (higher BMI-SDS in males) and glycaemia (lower glycaemia with higher BMI-SDS) (all $p<0.001$ ).

\section{Discussion}

Previous reports have documented heterogeneity in inaugural manifestation of type 1 diabetes according to age at diagnosis [3-6]. The present study confirmed that in immune-mediated diabetes before age 40, C-peptide levels were overall inversely correlated with parameters of more severe clinical presentation such as insulin needs, glycaemia at diagnosis and ketonuria. After adjustment for age and other age-related confounders, the present study has documented that male subjects with immune-mediated diabetes had overall less-preserved C-peptide levels as compared with female patients. This observation is exactly the opposite of previous findings in a smaller group of patients [11]. Furthermore, at variance with a study in children [12], but in agreement with findings in nondiabetic subjects [13], C-peptide levels were higher in the high-incidence period (October to March) as compared with the low-incidence period (April to September) [7]. The lack of association between C-peptide levels around diagnosis and $H L A-D Q$ risk status confirms our previous finding in adult-onset patients [10], but contrasts with grading of inaugural disease severity according to HLA$D Q$-linked risk in Finnish children [14]. We believe that these discrepancies with previous studies may be due to our use of multivariate analysis and/or a larger sample size, including a wider age range.

Our results may indicate that overall functional beta cell mass needs to be more reduced in males than in females to produce type 1 diabetes, since no sex-dependent differences in C-peptide levels have been noted in healthy controls [15]. However, the observed interactions indicated that in patients with better-preserved C-peptide levels, who are overall older at diagnosis, male subjects had a lessdecreased BMI-SDS and lower insulin needs than female patients. Of note, we previously found that the male excess in type 1 diabetes is restricted to the high-incidence period
[7], which now appears to be associated with betterpreserved C-peptide levels. This is in keeping with our hypothesis [5] that in immune-mediated type 1 diabetes an increased metabolic burden, e.g. due to insulin resistance linked to (central) obesity, may accelerate clinical onset in a subgroup of young male patients, thereby explaining the post pubertal male excess, which contrasts with the female preponderance in other autoimmune diseases [3, 5]. Arguments supporting this hypothesis include: (1) male excess in type 1 diabetes restricted to the high-incidence period [7]; (2) seasonality only observed for male patients above age 10 lacking the high-risk $H L A-D Q 2 / D Q 8$ genotype [7]; (3) an overall increased BMI-SDS compared with age- and sex-matched controls in male antibodypositive relatives but not in female and/or antibodynegative relatives [5]; (4) seasonality at diagnosis and a striking male excess also in antibody-negative diabetes diagnosed before age 40 [5,7]; and (5) a trend towards earlier presentation in male, but not in female, subjects in Belgium [4].

Our study has several strengths: a large representative group of Belgian type 1 diabetic patients [4] was included on the basis of autoantibody-positivity objectifying the presence of immune-mediated type 1 diabetes. On the other hand, our study is limited by the fact that blood samples for C-peptide were taken at random and not always at the clinical onset of the disease (i.e. within 7 days of insulin treatment), the fact that not all patients had a complete dataset, and the cross-sectional nature of the study.

In conclusion, we have documented that at diagnosis of type 1 diabetes C-peptide levels are overall lower in male than in female patients and in summer than in winter. Sexand season-dependent differences in residual beta cell mass and/or insulin resistance are likely to reflect aetiological heterogeneity and should be further investigated in longitudinal studies in prediabetes to further identify putative external triggers or lifestyle factors, which may provide targets for prevention.

Acknowledgements We are indebted to N. Alaerts, V. Baeten, M. Bodson, M. Carpentier, A. Ceusters, N. Christophe, E. De Man, A. Demarré, T. Demesmaeker, S. De Neve, L. De Pree, N. Diependaele, S. Exterbille, T. Ghysels, P. Goubert, C. Groven, A. Hutse, A. Ivens, D. Kesler, C. Lauwers, F. Lebleu, M. Lichtert, J. Michiels, H. Morobé, E. Quartier, A. Rawoens, A. Schoonis, G. Schoonjans, S. Schrans, M. Vanderlinden, S. Vanderstraeten, J. Van Elven and J. Vertommen for excellent technical assistance. The present work was supported by the Belgian Fonds voor Wetenschappelijk Onderzoek (grants 3-0113-97, 3-0456-99, G-0319-01, G-0517-04 and Levenslijn-Diabetes project 7.0021.96) and by Bayer, Eli Lilly, Life Scan, Novo Nordisk, Ortho Clinical Diagnostics and Roche. The central unit of the BDR is supported financially by grants from the Ministries of Public Health of the Flemish and French Community. We thank the Vlaamse Diabetes Vereniging, the Association Belge du Diabète and all members of the BDR for their invaluable help in recruiting diabetic patients and first-degree relatives and/or in the handling of blood samples.

Conflict of interest statement The authors are not aware of any conflict of interest. 


\section{References}

1. Leslie RDG, Elliott RB (1994) Early environmental events as a cause of IDDM. Evidence and implications. Diabetes 43:843-850

2. Soltész G (2003) Diabetes in the young: a paediatric and epidemiological perspective. Diabetologia 46:447-454

3. Gale EA, Gillespie KM (2001) Diabetes and gender. Diabetologia 44:3-15

4. Weets I, De Leeuw IH, Du Caju MV et al (2002) The incidence of type 1 diabetes in the age group 0-39 years has not increased in Antwerp (Belgium) between 1989 and 2000: evidence for earlier disease manifestation. Diabetes Care 25:840-846

5. Weets I, Van Autreve J, Van der Auwera BJ et al (2001) Maleto-female excess in diabetes diagnosed in early adulthood is not specific for the immune-mediated form nor is it HLA-DQ restricted: possible relation to increased body mass index. Diabetologia 44:40-47

6. Karjalainen J, Salmela P, Ilonen J, Surcel H-M, Knip M (1989) A comparison of childhood and adult type 1 diabetes mellitus. N Engl J Med 320:881-886

7. Weets I, Kaufman L, Van der Auwera B et al (2004) Seasonality in clinical onset of type 1 diabetes in Belgian patients above age 10 is restricted to HLA-DQ2/DQ8-negative males, which explains the male to female excess in incidence. Diabetologia 47:614-621

8. Cole TJ, Freeman JV, Preece MA (1995) Body mass index reference curves for the UK, 1990. Arch Dis Child 73:25-29
9. Decochez K, De Leeuw IH, Keymeulen B et al (2002) IA-2 autoantibodies predict impending type 1 diabetes in siblings of patients. Diabetologia 45:1658-1666

10. Weets I, Siraux V, Daubresse JC et al (2002) Relation between disease phenotype and HLA-DQ genotype in diabetic patients diagnosed in early adulthood. J Clin Endocrinol Metab 87:2597-2605

11. Pozzilli P, Mesturino CA, Crino A et al (2001) Is the process of beta-cell destruction in type 1 diabetes at time of diagnosis more extensive in females than in males? Eur $\mathrm{J}$ Endocrinol 145:757-761

12. Ludvigsson J, Afoke AO (1989) Seasonality of type 1 (insulindependent) diabetes mellitus: values of C-peptide, insulin antibodies and haemoglobin Alc show evidence of a more rapid loss of insulin secretion in epidemic patients. Diabetologia 32:84-91

13. Fahlen M, Oden A, Bjorntorp P, Tibblin G (1971) Seasonal influence on insulin secretion in man. Clin Sci 41:453-458

14. Veijola R, Knip M, Reijonen H, Vahasalo P, Puukka R, Ilonen J (1995) Effect of genetic risk load defined by HLA-DQB1 polymorphism on clinical characteristics of IDDM in children. Eur J Clin Invest 25:106-112

15. Service FJ, O'Brien PC, Kao PC, Young FWJR (1992) C-peptide suppression test: effects of gender, age and body mass index; implications for the diagnosis of insulinoma. J Clin Endocrinol Metab 74:204-210 